\title{
Internal traction method using a spring-and-loop with clip (S-O clip) allows countertraction in gastric endoscopic submucosal dissection
}

\author{
Mitsuru Nagata ${ }^{1}$
}

Received: 28 May 2019 / Accepted: 22 April 2020 / Published online: 29 April 2020

(c) The Author(s) 2020

\begin{abstract}
Background Insufficient countertraction and poor field of vision make endoscopic submucosal dissection (ESD) difficult. Internal traction method using a spring-and-loop with clip (SLC) allows sufficient traction in any direction and good field of vision. However, the attachment procedure is difficult and interference with the endoscope can occur in the retroflexed endoscopic position. We have developed a new use of SLC that simplifies the attachment procedure, eliminating interference with the endoscope. The aim of this study was to investigate the efficacy of SLC for gastric ESD.

Methods We retrospectively recruited 140 patients with gastric neoplasms who underwent ESD between November 2015 and October 2018 at our department. Among them, 51 patients treated using SLC-assisted ESD (SLC-ESD) and 89 patients treated using conventional ESD (C-ESD) were compared. Propensity score matching was performed to compensate for the differences in age, sex, lesion location, lesion position, specimen size, and ulcer findings. The primary outcome was ESD procedure time.

Results Propensity score matching generated 51 matched pairs. The procedure time in the SLC-ESD group was significantly shorter than that in the C-ESD group (median [interquartile], 40.0 [27.0-81.5] minutes versus 69.0 [46.5-113.5] minutes, $P=0.008$ ). The mean SLC attachment time was $2.08 \mathrm{~min}$. There were no significant differences in complete en bloc resection rate between SLC-ESD and C-ESD groups (100\% versus 96.1\%, $P=0.495)$. There were not perforation cases in either group. Conclusions SLC may offer an efficient method for gastric ESD, with a short attachment procedure time.
\end{abstract}

Keywords S-O clip · Internal traction method · Gastric endoscopic submucosal dissection · Gastric ESD · Countertraction · Propensity score matching analysis

In Japan, endoscopic submucosal dissection (ESD) is the standard therapy for gastric neoplasms, gradually spreading all over the world. ESD allows en bloc resection regardless of whether the lesion size is considered unresectable with endoscopic mucosal resection (EMR), resulting in precise pathological assessment and a lower recurrence rate [1]. However, ESD remains a challenging procedure due to technical difficulty and a long procedure time [2]. During regular surgery, surgeons use the non-dominant hand to

Electronic supplementary material The online version of this article (https://doi.org/10.1007/s00464-020-07590-9) contains supplementary material, which is available to authorized users.

Mitsuru Nagata

mitsuru10jp@yahoo.co.jp

1 Department of Endoscopy, Shonan Fujisawa Tokushukai Hospital, 1-5-1, Tsujidoukandai, Fujisawa-shi, Kanagawa, Japan provide sufficient countertraction and proper field of vision for the lesion while they efficiently dissect using the dominant hand. In contrast, endoscopists cannot put their hand into the gastrointestinal tract; therefore, it is not possible to provide countertraction to the lesion using non-dominant hand in ESD. It is like cutting a paper with scissors using only the dominant hand, without holding the paper by the non-dominant hand. Although a hood attached to the endoscope or gravity is used to obtain countertraction and field of vision, it is sometimes insufficient. Therefore, various traction methods have been developed [3]. However, in most traction methods, the direction of traction is limited, while the interference between the endoscope and the traction device is unavoidable.

The usefulness of spring-and-loop with clip-assisted ESD (SLC-ESD) using an S-O clip (Fig. 1; Zeon Medical, Tokyo, Japan) for colorectal neoplasms has been reported [4-6]. The S-O clip has been developed as a novel device 
for establishing internal traction in the forward endoscopic position for colorectal ESD, allowing traction in any direction. The $\mathrm{S}-\mathrm{O}$ clip is considered useful for not only colorectal ESD but also gastric ESD. However, the problems with the $\mathrm{S}-\mathrm{O}$ clip are the technical difficulty during attachment and interference between the endoscope and the spring of the $\mathrm{S}-\mathrm{O}$ clip in the retroflexed endoscopic position. In gastric ESD, submucosal dissection is frequently performed in the retroflexed endoscopic position, unlike colorectal ESD. Therefore, we have described a new use of the S-O clip which simplifies the attachment procedure, eliminating the interference between the endoscope and the spring of the $\mathrm{S}-\mathrm{O}$ clip in the retroflexed endoscopic position [7]. The current study aimed to investigate the efficacy of the S-O clip for gastric ESD.

\section{Materials and Methods}

\section{Patients}

This study was a retrospective and observational study. We retrospectively collected data from medical records and endoscopic reports at Shonan Fujisawa Tokushukai Hospital (Kanagawa, Japan). The patient enrollment process in this study is presented as a flowchart (Fig. 2). Between November 2015 and October 2018, 153 patients with 170 gastric neoplasms (such as early gastric cancers or gastric adenomas) underwent ESD at our department. Among them, six lesions located in the remnant stomach after gastrectomy were excluded from this study because ESD is difficult to perform in the remnant stomach [8]. Ten lesions treated using ESD with traction methods other than SLC-ESD were also excluded. In cases of multiple lesions, only the lesion that was treated first was included and other lesions were

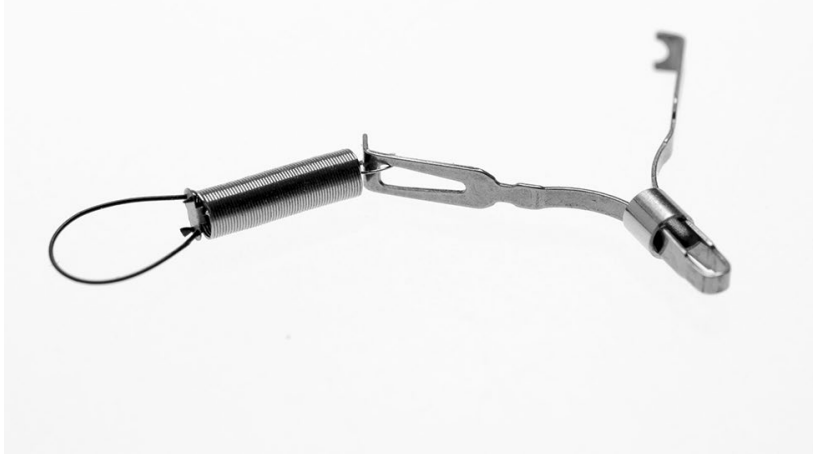

Fig. 1 The S-O clip has a 5-mm-long spring and 4-mm-long nylon loop at one side of the clip claws excluded from the study; hence, 14 lesions were excluded. Finally, 140 patients with 140 lesions who underwent ESD were retrospectively studied. The patients were divided into two groups according to their treatment approach: the SLCESD group (51 patients who underwent SLC-ESD using the S-O clip) and the C-ESD group (89 patients who underwent conventional ESD as a control group).

All ESD procedures were performed by a single endoscopist (M.N.). All lesions were evaluated histologically by forceps biopsy before ESD. We performed ESD for early gastric cancers without the possibility of lymph node metastasis, according to Japanese guidelines: (1) clinically intramucosal (cT1a) differentiated carcinomas of any size, without ulcer findings; (2) cT1a differentiated carcinomas, $\leq 30 \mathrm{~mm}$ in size with ulcer findings; (3) cT1a undifferentiated carcinomas, $\leq 20 \mathrm{~mm}$ in size, without ulcer findings [9]. Even if submucosal invasion was suspected, ESD was performed if the patient strongly desired ESD instead of surgery. Gastric adenomas at high risk of canceration also underwent ESD.

\section{Propensity score matching analysis}

Propensity score matching analysis was performed to minimize sampling bias and potential confounding. Previous reports have demonstrated that lesion location at the upper-third of the stomach, lesion position at the greater curvature, large specimen size, and the presence of ulcer findings make gastric ESD technically difficult, resulting in long ESD procedure times [10-13]. Thus, propensity score was calculated using a logistic regression model with the ESD procedure (SLC-ESD group or C-ESD group) as an objective variable; lesion location (upper-third of the stomach or others), lesion position (greater curvature of the stomach or others), specimen size, ulcer findings (presence or absent), and basic patient variables, including age and sex as explanatory variables. The SLC-ESD and C-ESD groups were matched according to the propensity scores using the following algorithm: 1:1 optimal match without a caliper and without replacement.

\section{Ethics}

The risks and benefits of the procedure were explained to all patients, and informed consent was obtained from all patients before ESD. The study protocol was approved by the central institutional review board and conformed with the ethical guidelines of the 1975 Declaration of Helsinki. 


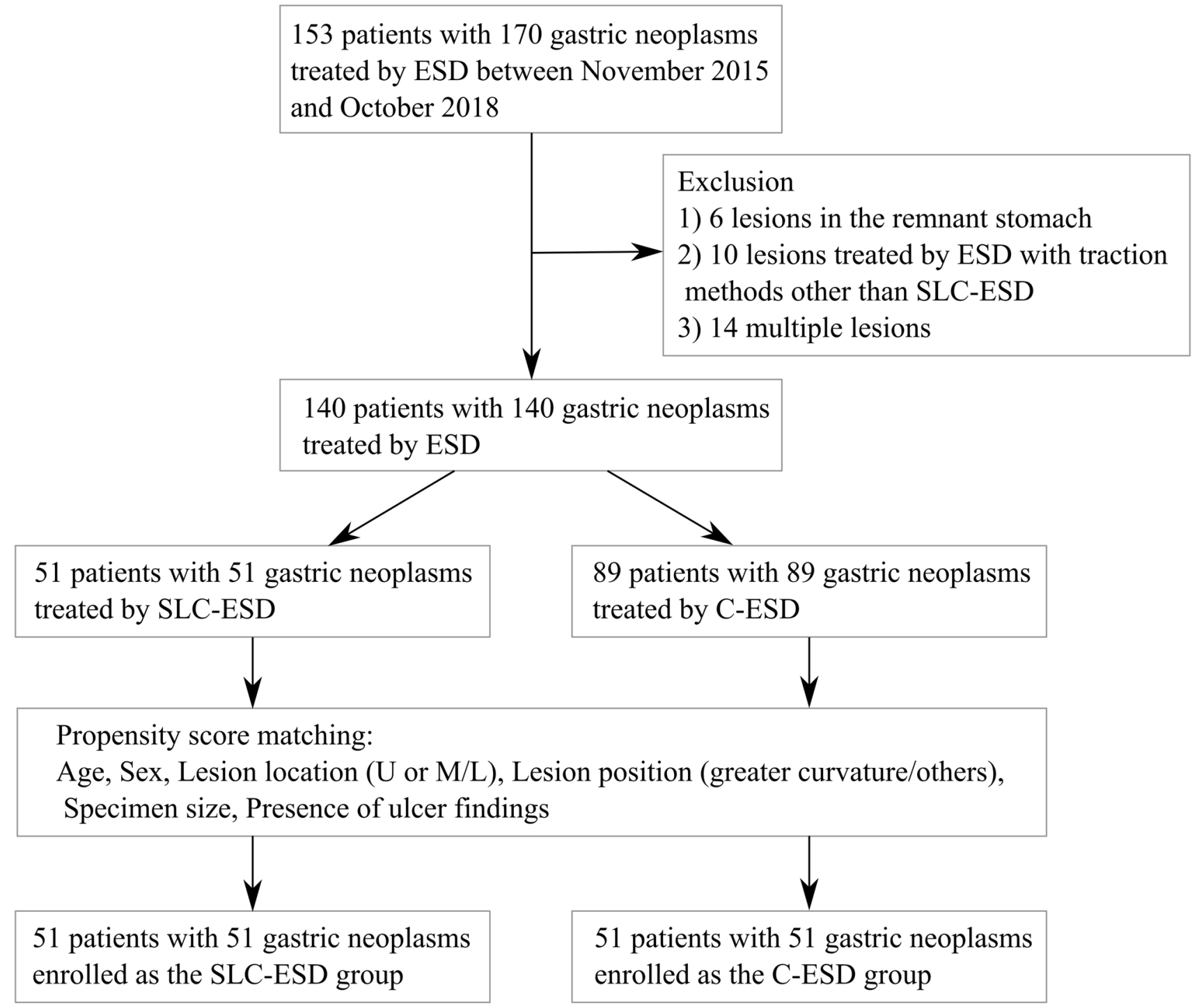

Fig. 2 Flowchart of patients enrolled in this study

\section{C-ESD procedure}

In the C-ESD group, the ESD procedure was performed as previously reported $[14,15]$. All patients were admitted on the day before ESD and observed in the hospital until the third day after ESD. The ESD procedure was performed under intravenous sedation using a single-channel endoscope (GIF-Q260J; Olympus, Tokyo, Japan). A transparent hood was attached to the tip of the endoscope to facilitate visualization of the field. Carbon dioxide $\left(\mathrm{CO}_{2}\right)$ insufflation was used to extend the stomach. An overtube (TOP, Tokyo, Japan) was used to reduce the risk of aspiration. A leak cutter (TOP) was attached to the overtube to maintain the distention of the stomach when $\mathrm{CO}_{2}$ leaked due to belching. A straight needle-type knife, DualKnifeJ (Olympus) or FlushKnifeBT (Fujifilm, Tokyo, Japan) was used as electrosurgical knife. CoagrasperG (Olympus) was used as hemostatic forceps. The VIO300D (ERBE Elektromedizin GmbH, Tüebingen, Germany) was used as an electrosurgical generator. Glycerin fructose solution (Hikari Pharmaceutical, Tokyo, Japan) was used as injection solution.

\section{SLC-ESD procedure}

In the SLC-ESD group, the $\mathrm{S}-\mathrm{O}$ clip was used as we have reported for gastric ESD [7]. The procedures that were performed without using the $\mathrm{S}-\mathrm{O}$ clip were the same as those performed during C-ESD. The margin of the part that had the possibility of $\mathrm{S}-\mathrm{O}$ clip attachment was set to be about 5-10 mm larger than that of C-ESD. With this larger margin, the $\mathrm{S}-\mathrm{O}$ clip was attached on the non-neoplastic area of specimen. This procedure prevents the difficulty for the 
pathological diagnosis due to the laceration of neoplastic area resulting from the slip-off of the S-O clip. After separating the lesion from the peripheral mucosa, the easier endoscopic position to perform submucosal dissection was selected from the forward or retroflexed endoscopic position.

If the retroflexed endoscopic position was selected, the procedure was as follows (Fig. 3, Video Case 1). The endoscope axis can interfere with the spring without devising an attachment method (Fig. 3A). The movement of the endoscope axis during submucosal dissection in the retroflexed endoscopic position was confirmed using a practice swing of the endoscope. The direction of spring extension and the anchor site were decided, such that the interference between the endoscope axis and the spring could be eliminated. The positional relationship between the endoscope axis, the direction in which the spring was going to extend, and the gastric wall was checked; in this case, the endoscope axis was at a lesser curvature and was closer to the posterior side of the spring extension direction (Fig. 3B). Maintaining this positional relationship can prevent the spring from overextension and loss of elasticity due to contact with the endoscope. The anchor site was marked with the electrosurgical knife. The S-O clip was attached on the anal edge of the lesion in which the loop came over the mucosa, which made it easy to hook the loop by the anchor clip (Fig. 3C). In contrast, with the conventional S-O clip attachment method, the loop comes under the mucosa [16]. The S-O clip loop was anchored in the forward endoscopic position after confirming the anchor site mark. Although it was possible to anchor in the retroflexed endoscopic position, it was frequently
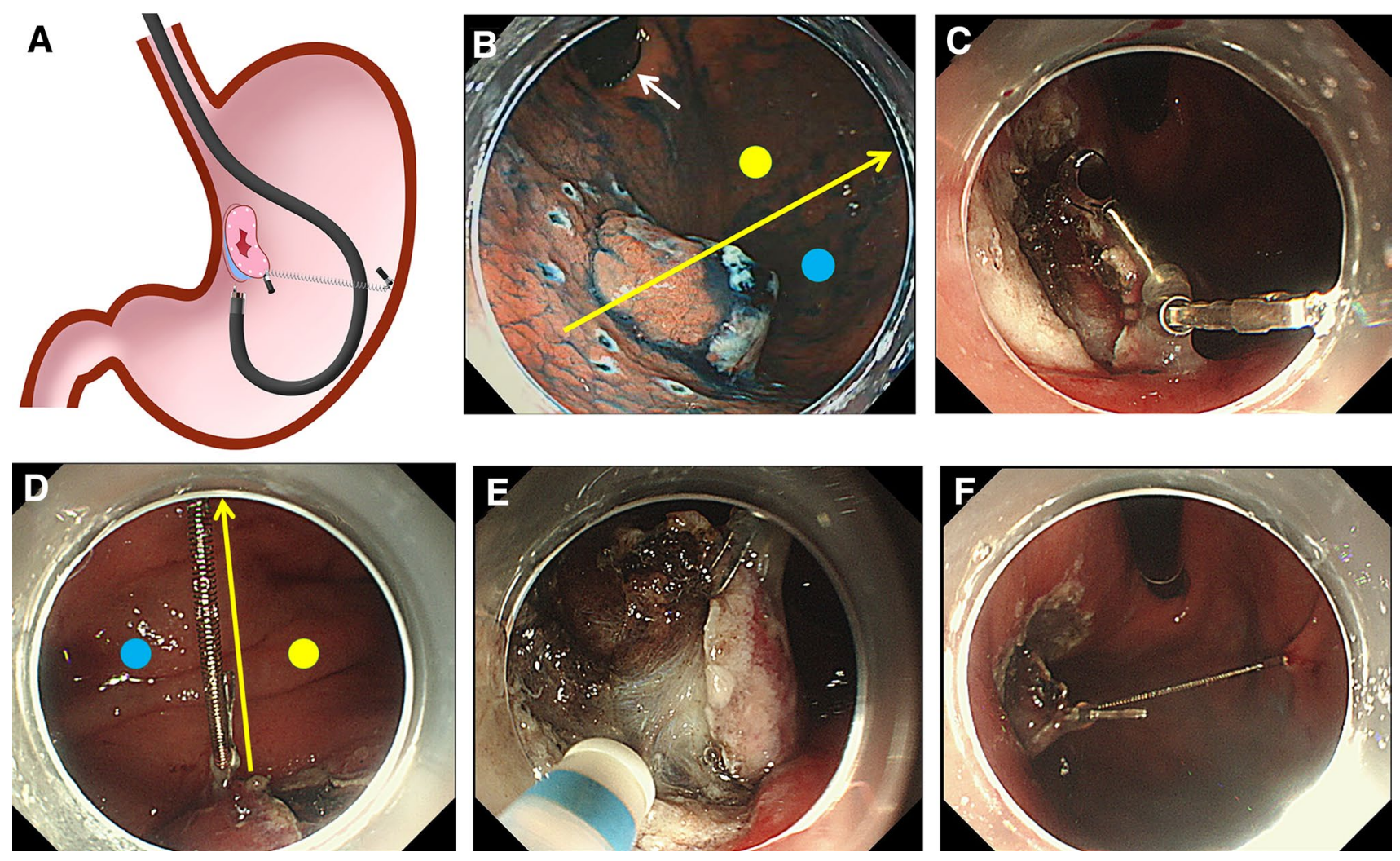

Fig. 3 SLC-ESD using the S-O clip in the retroflexed endoscopic position for an elevated lesion, $20 \mathrm{~mm}$ in diameter, located at the posterior wall closer to the greater curvature side of the upper gastric body (Video Case 1). A The endoscope axis may interfere with the spring in the retroflexed endoscopic position without devising an attachment method. B The movement of the endoscope axis during submucosal dissection in the retroflexed endoscopic position was confirmed using a practice swing of the endoscope. The yellow arrow represents the direction of the spring extension preventing interference with the endoscope axis. The white arrow represents the endoscope axis. The yellow dot represents the lesser curvature side of the yellow arrow. The blue dot represents the greater curvature side of the yellow arrow. Note the positional relationship in which the endoscope axis is at the yellow dot side of the yellow arrow. C After separating the lesion from the peripheral mucosa, the $\mathrm{S}-\mathrm{O}$ clip is attached on the anal side of the lesion such that the loop comes over the mucosa. D The loop of the $\mathrm{S}-\mathrm{O}$ clip is anchored on the opposite side of the lesion in the forward view. The yellow arrow represents the spring extension direction. The yellow dot represents the lesser curvature side of the yellow arrow. The blue dot represents the greater curvature side of the yellow arrow. The endoscope position is changed to the retroflexed position after going through the yellow dot side of the yellow arrow, maintaining the positional relationship in which the endoscope axis is at the yellow dot side of the yellow arrow. E Extension of the spring provides appropriate traction and good visualization of the submucosa. F The interference between the endoscope and the spring is preventable 
difficult owing to poor maneuverability. The endoscopic position was carefully changed to the retroflexed position after going through the space between the spring and gastric wall so as to indicate a positional relationship that the endoscope axis was at the lesser curvature closer to the posterior side of the spring extension direction, to prevent slinging over the spring (Fig. 3D). Finally, the submucosal dissection was started with good field of vision (Fig. 3E), preventing interference between the endoscope and spring (Fig. 3F).

If the forward endoscopic position was selected, the procedure was as follows (Fig. 4, Video Case 2). Interference between the endoscope and the spring of the $\mathrm{S}-\mathrm{O}$ clip during submucosal dissection rarely occurs (Fig. 4A). After separation of the lesion from the peripheral mucosa,

A
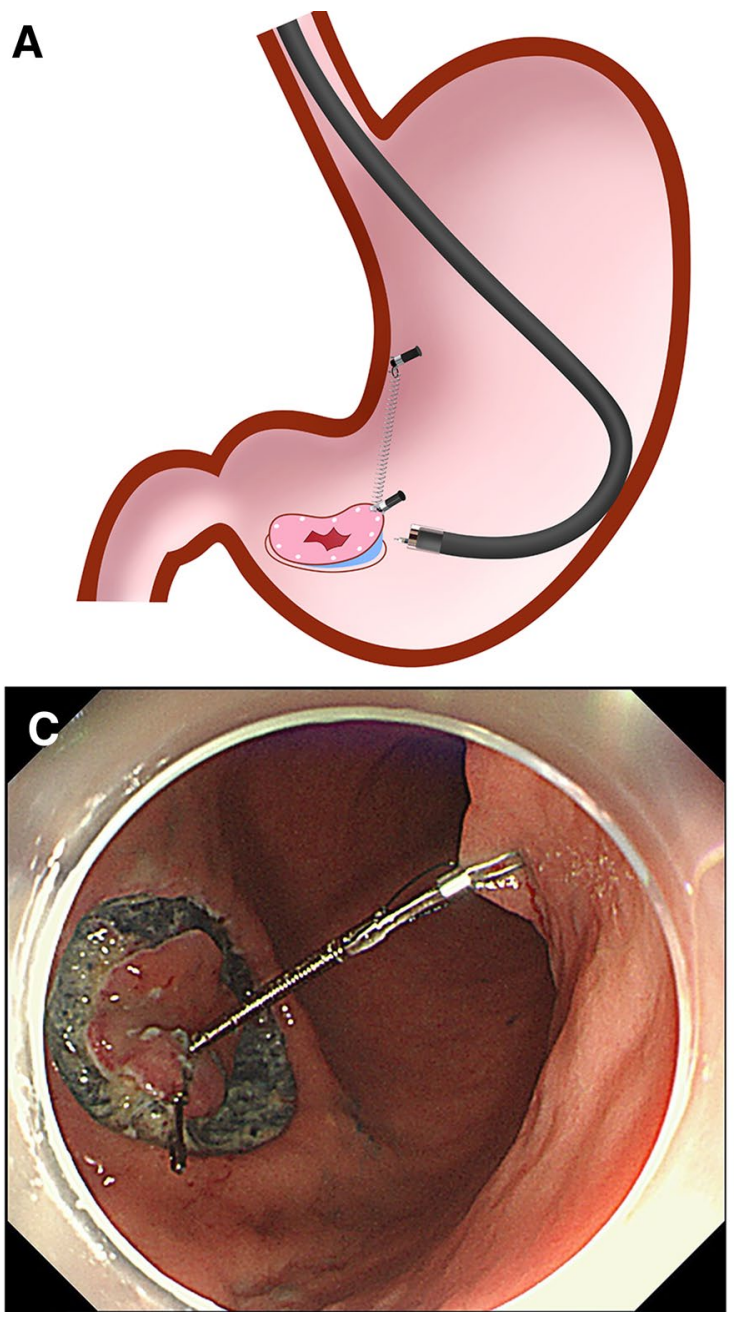

Fig. 4 SLC-ESD using the S-O clip in the forward endoscopic position for a flat lesion, $10 \mathrm{~mm}$ in diameter, located at the anterior wall closer to the greater curvature side of the lower gastric body (Video Case 2). A Interference between the endoscope and spring during submucosal dissection rarely occurs. B After separation of the lesion from the peripheral mucosa, the $\mathrm{S}-\mathrm{O}$ clip is attached on the oral side of the lesion such that the loop comes over the mucosa, mak- the S-O clip was attached on the oral side of the lesion such that the loop came over the mucosa, which made it easy to hook the loop by the anchor clip (Fig. 4B). The loop of the $\mathrm{S}-\mathrm{O}$ clip was anchored on the opposite side of the lesion (Fig. 4C). Finally, submucosal dissection was started (Fig. 4D).

When the head of the $\mathrm{S}-\mathrm{O}$ clip fell down after attachment, it was used to turn over the mucosal flap similar to that in the clip flap method [17]. If the traction force became weak during submucosal dissection, an additional S-O clip was attached. After complete dissection, the anchor clip was removed using forceps, and the specimen with the $\mathrm{S}-\mathrm{O}$ clip was extracted out from the body.
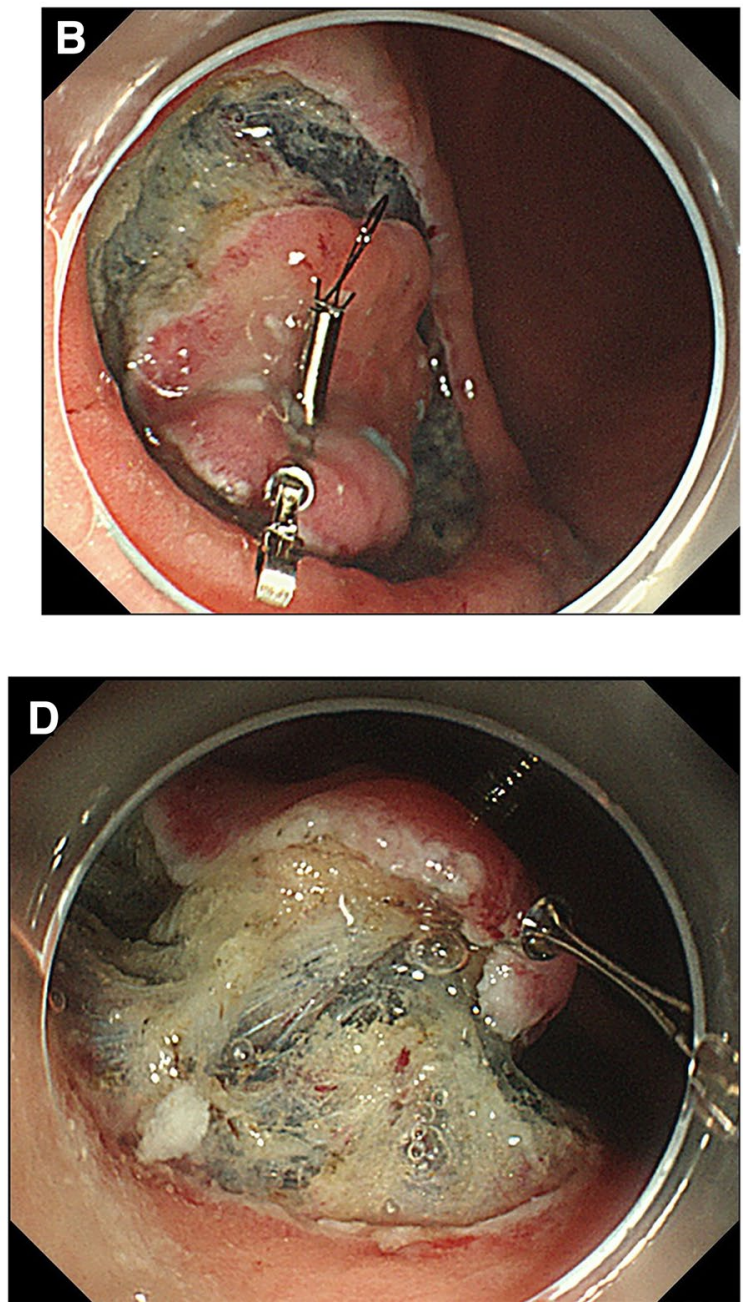

ing it easy to hook the loop by the anchor clip. C The loop of the $\mathrm{S}-\mathrm{O}$ clip is anchored on the opposite side of the lesion. D Extension of the spring provides appropriate traction and good visualization of the submucosa. When the head of the $\mathrm{S}-\mathrm{O}$ clip fall down after attachment, it is used to turn over the mucosal flap similar to that in the clip flap method 


\section{Outcomes}

The primary outcome of this study was procedure time. Secondary outcomes were dissection speed, en bloc resection rate, complete resection rate, post-ESD bleeding rate, and perforation rate. Subgroup analysis for procedure time was performed according to the lesion location, position, and size. Subgroup analysis for endoscopic position during submucosal dissection was also performed according to the lesion location. In the SLC-ESD group, we also evaluated S-O clip-related factors, including S-O clip attachment time, S-O clip slip-off, number of S-O clip applications, $\mathrm{S}-\mathrm{O}$ clip reattachment, $\mathrm{S}-\mathrm{O}$ clip-related damage to the specimen, and successful removal rate of anchor clip. To examine the learning curve of S-O clip attachment, the SLC-ESD group $(n=51)$ was divided into the first half (case number: 1-25) and the second half (case number: 26-51), and S-O clip attachment time was compared.

\section{Definitions}

The length (mm) of the longer axis and the shorter axis of the resected specimen was measured after pinning on the board. The specimen size was defined as the longer axis length of the resected specimen. The specimen area $\left(\mathrm{mm}^{2}\right)$ was calculated using the ellipse formula: area $=$ (shorter axis length $) / 2 \times($ longer axis length $) / 2 \times 3.14$. The procedure time ( $\mathrm{min}$ ) was defined as the time from the first injection to the completion of the submucosal dissection, including the S-O clip attachment time. The dissection speed $\left(\mathrm{mm}^{2} /\right.$ min) was defined as the specimen area divided by the procedure time. En bloc resection was defined as the removal of the neoplastic area in a single piece. Complete resection was defined as en bloc resection with negative margin at both the horizontal and vertical cut end pathologically. PostESD bleeding was defined as the bleeding after ESD that required endoscopic hemostasis. Perforation was diagnosed by endoscopic findings such as the visualization of tissue outside the serosa during ESD procedure or the presence of free air under the diaphragm on the X-ray taken in a standing position performed as a routine on the day after ESD. Perforation included intraoperative and delayed perforation. $\mathrm{S}-\mathrm{O}$ clip attachment time was defined as the time from the appearance of the clip applicator on the monitor to completion of anchoring the loop of the $\mathrm{S}-\mathrm{O}$ clip on the gastric wall. If an $\mathrm{S}-\mathrm{O}$ clip reattachment was performed, the time required for reattachment was also included in the S-O clip attachment time. The $\mathrm{S}-\mathrm{O}$ clip-related damage to specimen was defined as dividing into two parts caused by the tension of the spring. Successful removal of anchor clip was defined as the point at which the anchor clip was extracted out from the body.

\section{Statistical analysis}

All statistical analyses were performed using $\mathrm{R}$ version 3.5.2 (R Foundation for Statistical Computing, Vienna, Austria). Categorical variables were analyzed using the Fisher exact test or the $\chi^{2}$ test. Continuous variables were analyzed using the Mann-Whitney $U$ test or the Student $t$ test. Differences between variables with $P<0.05$ were considered statistically significant.

\section{Results}

\section{Baseline characteristics and treatment outcomes before propensity score matching}

Table 1 shows the baseline characteristics, and Table 2 shows the treatment outcomes before propensity score matching. There were no significant differences in the baseline characteristics and treatment outcomes, except for dissection speed and specimen size. The median dissection speed in the SLC-ESD group was significantly faster than that in the C-ESD group (21.8 [interquartile range [IQR], 13.9-32.9] $\mathrm{mm}^{2} / \mathrm{min}$ versus 12.3 [IQR, $\left.8.2-15.5\right] \mathrm{mm}^{2} / \mathrm{min}, P<0.001$ ), although the median specimen size in the SLC-ESD group was significantly larger than that in the C-ESD group (38.0

Table 1 Baseline characteristics before propensity score matching

\begin{tabular}{llll}
\hline & $\begin{array}{l}\text { SLC-ESD } \\
n=51\end{array}$ & $\begin{array}{l}\text { C-ESD } \\
n=89\end{array}$ & $P$ value \\
\hline Mean age, years (SD) & $73.2(9.6)$ & $73.6(9.3)$ & 0.802 \\
Sex (male) & $62.7(32)$ & $69.7(62)$ & 0.456 \\
Median lesion size, mm & $15.0(8.5-21.5)$ & $12.0(8.0-18.0)$ & 0.07 \\
$\quad$ IQR) & & & \\
Lesion location & & & 0.223 \\
Upper & $19.6(10)$ & $10.1(9)$ & \\
Middle & $41.2(21)$ & $40.5(36)$ & \\
Lower & $39.2(20)$ & $49.4(44)$ & \\
Lesion position & & & \\
Greater curvature & $25.5(13)$ & $18.0(16)$ & \\
Lesser curvature & $33.3(17)$ & $30.3(27)$ & \\
Anterior wall & $19.6(10)$ & $27.0(24)$ & \\
Posterior wall & $21.6(11)$ & $24.7(22)$ & \\
Morphology & & & \\
$\quad$ Depressed & $68.6(35)$ & $60.7(54)$ & \\
Flat & $27.5(14)$ & $33.7(30)$ & \\
Protruded & $3.9(2)$ & $5.6(5)$ & \\
\hline
\end{tabular}

Values are $\%(n)$ unless otherwise indicated

$S L C$-ESD spring-and-loop with clip-assisted endoscopic submucosal dissection, $C$-ESD conventional endoscopic submucosal dissection, $S D$ standard deviation, $I Q R$ interquartile range 
Table 2 Treatment outcomes before propensity score matching

\begin{tabular}{|c|c|c|c|}
\hline & $\begin{array}{l}\text { SLC-ESD } \\
n=51\end{array}$ & $\begin{array}{l}\text { C-ESD } \\
n=89\end{array}$ & $P$ value \\
\hline Histology & & & 0.695 \\
\hline Adenoma & $13.7(7)$ & $9.0(8)$ & \\
\hline Differentiated adenocarcinoma & $82.4(42)$ & $86.5(77)$ & \\
\hline Undifferentiated adenocarcinoma & $3.9(2)$ & $4.5(4)$ & \\
\hline Depth & & & 0.440 \\
\hline Mucosa* & $84.3(43)$ & $80.9(72)$ & \\
\hline Submucosa $(<500 \mu \mathrm{m})$ & $9.8(5)$ & $6.7(6)$ & \\
\hline Submucosa $(\geqq 500 \mu \mathrm{m})$ & $5.9(3)$ & $12.4(11)$ & \\
\hline Presence of ulcer findings & $15.7(8)$ & $6.7(6)$ & 0.141 \\
\hline Median procedure time, $\min (\mathrm{IQR})$ & $40.0(27.0-81.5)$ & $53.0(37.0-78.0)$ & 0.157 \\
\hline Median dissection speed, $\mathrm{mm}^{2} / \mathrm{min}$ (IQR) & $21.8(13.9-32.9)$ & $12.3(8.2-15.5)$ & $<0.001^{\dagger}$ \\
\hline Median specimen size, mm (IQR) & $38.0(32.0-45.0)$ & $30.0(27.0-35.0)$ & $<0.001^{\dagger}$ \\
\hline En bloc resection & $100(51)$ & $100(89)$ & NA \\
\hline Complete resection & $100(51)$ & $97.8(87)$ & 0.534 \\
\hline Post-ESD bleeding & $2.0(1)$ & $3.4(3)$ & 1.000 \\
\hline Perforation & $0(0)$ & $0(0)$ & NA \\
\hline \multicolumn{4}{|l|}{$\mathrm{S}-\mathrm{O}$ clip-related factors } \\
\hline Mean S-O clip attachment time, min (SD) & $2.08(1.32)$ & NA & NA \\
\hline S-O clip slip-off & $3.9(2)$ & NA & NA \\
\hline Mean number of S-O clip applications, (SD) & $1.22(0.54)$ & NA & NA \\
\hline $\mathrm{S}-\mathrm{O}$ clip reattachment & $17.6(9)$ & NA & NA \\
\hline $\mathrm{S}-\mathrm{O}$ clip-related damage to specimen & $0(0)$ & NA & NA \\
\hline Successful removal of anchor clip & $92.2(47)$ & NA & NA \\
\hline
\end{tabular}

Values are \% (n) unless otherwise indicated

$S L C$-ESD spring-and-loop with clip-assisted endoscopic submucosal dissection, $C$ - $E S D$ conventional endoscopic submucosal dissection, $S D$ standard deviation, IQR interquartile range, $N A$ not applicable

*Intramucosal cancers and adenomas are included in this category

${ }^{\dagger} P<0.05$
[IQR, 32.0-45.0] $\mathrm{mm}$ versus 30.0 [IQR, 27.0-35.0] mm, $P<0.001)$.

The mean S-O clip attachment time was $2.08 \mathrm{~min}$ (standard deviation [SD], 1.32). There were no significant differences in the mean S-O clip attachment time between the first half and the second half of the SLC-ESD group (2.05 min [SD, 1.42] versus $2.12 \mathrm{~min}$ [SD, 1.23], $P=0.942$ ). Reattachment was required 11 times in nine patients in the SLC-ESD group for the following reasons: to add traction force ( 8 times), failure to attach the $\mathrm{S}-\mathrm{O}$ clip to the lesion (1 time), and S-O clip slip-off ( 2 times). The rate of successful removal of anchor clip was $92.2 \%$.

\section{Propensity score matching evaluation}

This propensity score model was reliable (Likelihood Ratio Test; $P<0.01$ ), well-calibrated (Hosmer-Lemeshow test; $P=0.39$ ), and demonstrated acceptable discrimination between the two groups ( $c$ statistic $=0.757)$. There was less probability of multicollinearity because all the variance inflation factors of explanatory variables were less than 1.2. All patients in the SLC-ESD group were matched with patients in the C-ESD group.

\section{Matching factors and treatment outcomes after propensity score matching}

Table 3 shows the treatment outcomes after propensity score matching. There were no significant differences in matching factors, including age, sex, specimen size, lesion location, lesion position, and the presence of ulcer findings between the two groups. The median procedure time in the SLC-ESD group was significantly shorter than that in the C-ESD group (40.0 [IQR, 27.0-81.5] min versus 69.0 [IQR, 46.5-113.5] min, $P=0.008)$. The median dissection speed in the SLCESD group was significantly faster than that in the C-ESD group (21.8 [IQR, 13.9-32.9] $\mathrm{mm}^{2} / \mathrm{min}$ versus 11.8 [IQR, $\left.7.6-16.0] \mathrm{mm}^{2} / \mathrm{min}, P<0.001\right)$. There were no significant differences in en bloc resection rate, complete resection rate, 
Table 3 Matching factors and treatment outcomes after propensity score matching

\begin{tabular}{llll}
\hline & $\begin{array}{l}\text { SLC-ESD } \\
n=51\end{array}$ & $\begin{array}{l}\text { C-ESD } \\
n=51\end{array}$ & $P$ value \\
\hline Matching factors & & & \\
Mean age, yers (SD) & $73.2(9.6)$ & $72.8(10.0)$ & 0.872 \\
Sex (male) & $62.7(32)$ & $56.9(29)$ & 0.687 \\
Median specimen size, mm (IQR) & $38.0(32.0-45.0)$ & $35.0(30.0-40.0)$ & 0.059 \\
Lesion location (Upper third) & $21.6(11)$ & $17.6(9)$ & 0.804 \\
Lesion position (Greater curvature) & $25.5(13)$ & $19.6(10)$ & 0.636 \\
Presence of ulcer findings & $15.7(8)$ & $7.8(4)$ & 0.357 \\
Treatment outcomes & & & \\
Median procedure time, min (IQR) & $40.0(27.0-81.5)$ & $69.0(46.5-113.5)$ & $0.008^{\dagger}$ \\
Median dissection speed, mm ${ }^{2} / \mathrm{min}(\mathrm{IQR})$ & $21.8(13.9-32.9)$ & $11.8(7.6-16.0)$ & $<0.001^{\dagger}$ \\
En bloc resection & $100(51)$ & $100(51)$ & $\mathrm{NA}$ \\
Complete resection & $100(51)$ & $96.1(49)$ & 0.495 \\
Post-ESD bleeding & $2.0(1)$ & $5.9(3)$ & 0.617 \\
Perforation & $0(0)$ & $0(0)$ & $\mathrm{NA}$ \\
\hline
\end{tabular}

Values are \% (n) unless otherwise indicated

$S L C$-ESD spring-and-loop with clip-assisted endoscopic submucosal dissection, $C$-ESD conventional endoscopic submucosal dissection, $S D$ standard deviation, IQR interquartile range, $N A$ not applicable

${ }^{\dagger} P<0.05$
post-ESD bleeding rate or perforation rate between the two groups.

Table 4 shows subgroup analysis between procedure time and lesion location, position, or size. The median procedure time for lesions located at the upper- or middle-third of the stomach or outside the greater curvature or for those that were $\leq 20 \mathrm{~mm}$ in size in the SLC-ESD group was significantly shorter than that in the C-ESD group. Table 5 shows subgroup analysis between endoscopic position during submucosal dissection and lesion location. The forward
Table 4 Subgroup analysis between procedure time and lesion location, position, or size

\begin{tabular}{|c|c|c|c|}
\hline & $\begin{array}{l}\text { SLC-ESD } \\
n=51\end{array}$ & $\begin{array}{l}\text { C-ESD } \\
n=51\end{array}$ & $P$ value \\
\hline \multicolumn{4}{|l|}{ Lesion location } \\
\hline Upper & $n=11$ & $n=9$ & \\
\hline Median procedure time, $\min (\mathrm{IQR})$ & $61.0(44.5-84.5)$ & $127.0(107.0-259.0)$ & $0.020^{\dagger}$ \\
\hline Middle & $n=20$ & $n=20$ & \\
\hline Median procedure time, $\min (\mathrm{IQR})$ & $40.0(33.0-89.5)$ & $90.0(60.8-123)$ & $0.011^{\dagger}$ \\
\hline Lower & $n=20$ & $n=22$ & \\
\hline Median procedure time, $\min (\mathrm{IQR})$ & $26.5(16.8-53.8)$ & $48.0(28.5-63.5)$ & 0.284 \\
\hline \multicolumn{4}{|l|}{ Lesion position } \\
\hline Greater curvature & $n=13$ & $n=10$ & \\
\hline Median procedure time, $\min (\mathrm{IQR})$ & $34.0(28.0-80.0)$ & $70.0(49.5-119.3)$ & 0.0938 \\
\hline Outside greater curvature & $n=38$ & $n=41$ & \\
\hline Median procedure time, $\min (\mathrm{IQR})$ & $44.5(26.0-82.3)$ & $69.0(47.0-109.0)$ & $0.0252^{\dagger}$ \\
\hline \multicolumn{4}{|l|}{ Lesion size } \\
\hline$>20 \mathrm{~mm}$ & $n=16$ & $n=16$ & \\
\hline Median procedure time, $\min (\mathrm{IQR})$ & $90(58.75-118.75)$ & $121(73.75-224.5)$ & 0.097 \\
\hline$\leq 20 \mathrm{~mm}$ & $n=35$ & $n=35$ & \\
\hline Median procedure time, $\min (\mathrm{IQR})$ & $34(21.5-54.5)$ & $57(38.5-91.5)$ & $<0.001^{\dagger}$ \\
\hline
\end{tabular}

$S L C$-ESD spring-and-loop with clip-assisted endoscopic submucosal dissection, $C$-ESD conventional endoscopic submucosal dissection, $S D$ standard deviation, IQR interquartile range, $N A$ not applicable

${ }^{\dagger} P<0.05$ 
Table 5 Subgroup analysis between endoscopic position during submucosal dissection and lesion location

\begin{tabular}{llll}
\hline & $\begin{array}{l}\text { SLC-ESD } \\
n=51\end{array}$ & $\begin{array}{l}\text { C-ESD } \\
n=51\end{array}$ & $P$ value \\
\hline Lesion location & & & \\
$\quad$ Upper & $n=11$ & $n=9$ & $0.014^{\dagger}$ \\
Forward endoscopic position & $54.5(6)$ & $0(0)$ & \\
Retroflexed endoscopic position & $45.5(5)$ & $100(9)$ & \\
$\quad$ Middle & $n=20$ & $n=20$ & 0.09 \\
Forward endoscopic position & $30(6)$ & $5(1)$ & \\
Retroflexed endoscopic position & $70(14)$ & $95(19)$ & \\
$\quad$ Lower & $n=20$ & $n=22$ & 0.333 \\
Forward endoscopic position & $85.0(17)$ & $95.5(21)$ & \\
Retroflexed endoscopic position & $15.0(3)$ & $4.5(1)$ & \\
\hline
\end{tabular}

Values are \% ( $n$ ) unless otherwise indicated

$S L C$-ESD spring-and-loop with clip-assisted endoscopic submucosal dissection, $C$-ESD conventional endoscopic submucosal dissection, $S D$ standard deviation, $I Q R$ interquartile range

${ }^{\dagger} P<0.05$

endoscopic position selected rate for lesions at the upperthird of stomach in the SLC-ESD group was significantly higher than that in the C-ESD group.

\section{Discussion}

The current study was undertaken to investigate the efficacy of the $\mathrm{S}-\mathrm{O}$ clip for gastric ESD. The results showed that the $\mathrm{S}-\mathrm{O}$ clip was significantly associated with shorter procedure time and faster dissection speed, while there were no significant differences in en bloc resection rate, complete resection rate, post-ESD bleeding rate or perforation rate.

The traction methods are classified as the external forceps method, double scope method, clip-and-snare method, internal traction method, and clip-with-line method [3]. However, these methods except for the clip-with-line method are not widely used due to limitations. The external forceps method [18] is difficult to use in cardia and the lesser curvature of upper gastric body. The double scope method [19] requires two endoscopists. The clip-and-snare method [20] has relatively strong interference with endoscope and traction direction is limited to the two ways. The internal traction method [21-23],SLC-ESD is classified in this category, has a relatively complicated procedure; thus, its use is not standardized in gastric ESD.

The clip-with-line method was reported in 2002 and one of the most popular traction methods in gastric ESD [24-27]. However, a recent multicenter randomized controlled trial reported that the clip-with-line method using a dental floss clip did not reduce the gastric ESD procedure time compared with conventional gastric ESD [27]. This is probably because traction direction of the clip-with-line method is limited to the oral side via cardia of stomach. Traction toward the oral side cannot provide countertraction when submucosal dissection is performed in the retroflexed endoscopic position, although gastric ESD is frequently performed in the retroflexed endoscopic position. In this situation, traction toward the anal side can provide countertraction. Simultaneously, it is also important that traction direction becomes near-vertical against muscle layer, because it helps to open the cutting edge and provide proper visualization of submucosa.

In contrast, the $\mathrm{S}-\mathrm{O}$ clip can provide traction in any direction both in the forward and retroflexed endoscopic positions; therefore, the $\mathrm{S}-\mathrm{O}$ clip may be useful anywhere in the stomach. Indeed, in the subgroup analysis, the procedure time of the SLC-ESD group at the upper- or middle-third of the stomach was significantly shorter than that in the C-ESD group. The reason why the procedure time of the SLC-ESD group at the lower-third of the stomach was not significantly shorter than that in the C-ESD group is that performing the ESD procedure on the lower-third of the stomach is generally easier than performing that on the upper- or middle-third of the stomach; moreover, it was difficult to make a statistical difference. The procedure time of the SLC-ESD group was not significantly shorter in lesions located at the greater curvature, although there is a tendency of shorter procedure time in the SLC-ESD group. This result is considered to be due to the insufficient number of cases.

According to the subgroup analysis between procedure time and lesion size, for lesions $\leq 20 \mathrm{~mm}$ in size, the median procedure time was shorter in the SLC-ESD group than in the C-ESD group. In contrast, for lesions $>20 \mathrm{~mm}$, there were no significant differences between the groups. This result suggests that the efficacy of SLC-ESD depends on the size of the lesion. In SLC-ESD, as the submucosal dissection advances, the distance between the $\mathrm{S}-\mathrm{O}$ clip attachment site and the anchor site decreases, the spring shrinks, and the traction force gradually weakens. If the lesion is small, submucosal dissection will be completed before the traction force becomes insufficient. In contrast, if the size of the lesion is large, the traction force weakens in the second half of the submucosal dissection, resulting in less benefit for SLC-ESD compared with C-ESD. Therefore, if the lesion size is large (e.g., $>20 \mathrm{~mm}$ ), operators should consider selecting an anchor site that is relatively far from the $\mathrm{S}-\mathrm{O}$ clip attachment position or adding a second $\mathrm{S}-\mathrm{O}$ clip on the way to submucosal dissection to strengthen the traction force.

For lesions that develop in anatomically narrow areas, such as those near the esophagogastric junction or pyloric ring, it is sometimes difficult to achieve both the traction toward the ideal direction and the appropriate distance between the S-O clip attachment position and the anchor 
site. Moreover, it is relatively difficult to guide the loop of $\mathrm{S}-\mathrm{O}$ clip to the anchor site using the regular clip because of the narrow working space. In such lesions, we preferentially selected the anchor site where a certain distance between the S-O clip attachment position and the anchor site could be obtained, and the loop of $\mathrm{S}-\mathrm{O}$ clip could be easily guided to the anchor site. With this procedure, the direction of the traction may slightly deviate from the ideal direction, or the strength of the traction may be slightly weakened; however, this is not a serious problem in most cases. Although it is necessary to be familiar with SLC-ESD, at present, we believe that SLC-ESD can be selected and used in all the parts of the stomach.

One SLC-ESD procedure needs one S-O clip and one regular clip as an anchor clip, which costs $¥ 5000$ and $¥ 750$ ( $\$ 50$ and $\$ 7.5$, if the exchange rate is $¥ 100=\$ 1$ ), respectively. In this study, the median procedure time was $40 \mathrm{~min}$ in the SLC-ESD group and $69 \mathrm{~min}$ in the C-ESD group, demonstrating approximately $40 \%$ reduction of median procedure time in SLC-ESD group. The S-O clip may provide an advantage in terms of cost, although the method of calculating medical costs is different in each country. Although SLC-ESD can be effective for lesions irrespective of their size and location, in consideration of cost and the results of subgroup analysis, SLC-ESD is recommended especially for the lesions that are $\leq 20 \mathrm{~mm}$ in size and located at the upperand middle-third of the stomach.

It is important to prevent interference between the endoscope and traction device, because interference causes strong traction, resulting in traction device slip-off, damage to the specimen and elevation of muscle layer. In the clip-withline method or clip-and-snare method, interference caused by the friction between the endoscope and traction device in the cardia cannot be eliminated. In SLC-ESD, interference rarely occurs in the forward endoscopic position, while interference in the retroflexed endoscopic position can be eliminated by devising an attachment procedure as stated in materials and methods section. Indeed, the $\mathrm{S}-\mathrm{O}$ clip slip-off rate was 3.9\%, occurring in only two cases in the SLC-ESD group. The clip slip-off rate of the clip-with-line method was reported to be $13.2 \%$ [27]; therefore, the S-O clip slipoff rate was relatively lower and permissible. The S-O clip reattachment was required in nine patients in the SLC-ESD group, as mentioned the results section, primarily to add traction force. The frequency of reattachments appears to be relatively high; however, this number may decrease as operators become more familiar with SLC-ESD.

Generally, the forward endoscopic position is non-preferred for the upper- or middle-third of stomach during C-ESD, because it is difficult to turn over the mucosal flap owing to the movement of the lesion caused by the patient's respiration. However, in subgroup analysis, the forward endoscopic position selected rate for the lesion located at the upper-third of stomach was significantly higher in the SLCESD group than in the C-ESD group. The forward endoscopic position selected rate for the lesion at middle-third of stomach also tended to be higher in the SLC-ESD group than in the C-ESD group, although there was no significant difference. These results suggest that the $\mathrm{S}-\mathrm{O}$ clip makes it easy to perform submucosal dissection for the lesion located at the upper- or middle-third of the stomach even in the forward endoscopic position, while it helps in turning over the mucosal flap. Moreover, interference between the endoscope and the spring rarely occurs in the forward endoscopic position during SLC-ESD. Therefore, the forward endoscopic position should be the first choice in SLC-ESD.

To the best of our knowledge, there is an only one retrospective cohort study about SLC-ESD using the S-O clip for gastric neoplasms [28]. However, the use of S-O clip in the retroflexed endoscopic position that is frequently selected in gastric ESD and the $\mathrm{S}-\mathrm{O}$ clip attachment method were not standardized. Our study demonstrated that using $\mathrm{S}-\mathrm{O}$ clip both in the forward and retroflexed endoscopic positions could be standardized, and the mean S-O clip attachment time was as short as $2.08 \mathrm{~min}$. In contrast, a previous study has reported that the mean S-O clip attachment time required was as long as $4.4 \mathrm{~min}$.[28] This was probably because the modified S-O clip attachment method [7] in which the loop came over the mucosa made it easy to hook the loop by the anchor clip; however, the loop came under the mucosa in the conventional attachment method [16]. There were no significant differences in mean S-O clip attachment time between the first half and the second half of SLC-ESD group. This result suggests that the modified S-O clip attachment method may be used without serious difficulties from the beginning of introduction by endoscopists who are accustomed to using hemoclips.

The management of anchor clip after SLC-ESD in the stomach is not standardized. In a previous report, the loop of the $\mathrm{S}-\mathrm{O}$ clip was cut to detach the resected specimen from the stomach [28]. However, in this procedure, there is a possibility that the anchor clip permanently remains on the gastric wall. The natural drop of the anchor clip from gastric wall could not be expected because vermiculation of stomach is poor except in the pars pylorica. The clamping ring of the anchor clip can be loosened using forceps to detach the anchor clip; however, it is time-consuming and not always successful. In this study, we attempted to detach the anchor clip from the gastric wall with forceps in all SLC-ESD cases, followed by extraction of the resected specimen with the $\mathrm{S}-\mathrm{O}$ clip and anchor clip. The successful removal rate of the anchor clip was $92.2 \%$, and there were no adverse events due to removal of anchor clip. In all failed removal cases, detaching the anchor clip was attempted more than one month after ESD. This failure probably resulted from submucosal fibrosis around the remaining anchor clip; 
therefore, it was considered better to remove the anchor clip immediately after ESD on the same day.

The current study has several limitations. First, this was a retrospective study with a limited number of patients. Second, propensity score matching analysis can decrease bias in causal estimates owing to observed differences between groups but are still subject to biases owing to unobserved differences. A randomized controlled trial is needed to evaluate the efficacy of the $\mathrm{S}-\mathrm{O}$ clip for gastric ESD.

In conclusion, the $\mathrm{S}-\mathrm{O}$ clip shortened the gastric ESD procedure time, allowing countertraction both in the forward and retroflexed endoscopic positions. Moreover, devising the usage of $\mathrm{S}-\mathrm{O}$ clip could eliminate the interference between the endoscope and the spring of S-O clip, simplifying the attachment procedure. Therefore, the $\mathrm{S}-\mathrm{O}$ clip has the potential to be the best traction device for gastric ESD.

Disclosure Dr. Mitsuru Nagata have no conflicts of interest or financial ties to disclose.

Open Access This article is licensed under a Creative Commons Attribution 4.0 International License, which permits use, sharing, adaptation, distribution and reproduction in any medium or format, as long as you give appropriate credit to the original author(s) and the source, provide a link to the Creative Commons licence, and indicate if changes were made. The images or other third party material in this article are included in the article's Creative Commons licence, unless indicated otherwise in a credit line to the material. If material is not included in the article's Creative Commons licence and your intended use is not permitted by statutory regulation or exceeds the permitted use, you will need to obtain permission directly from the copyright holder. To view a copy of this licence, visit http://creativecommons.org/licenses/by/4.0/.

\section{References}

1. Suzuki H, Oda I, Abe S, Sekiguchi M, Mori G, Nonaka S, Yoshinaga S, Saito Y (2016) High rate of 5-year survival among patients with early gastric cancer undergoing curative endoscopic submucosal dissection. Gastric Cancer 19:198-205

2. Rosch T, Sarbia M, Schumacher B, Deinert K, Frimberger E, Toermer T, Stolte M, Neuhaus H (2004) Attempted endoscopic en bloc resection of mucosal and submucosal tumors using insulatedtip knives: a pilot series. Endoscopy 36:788-801

3. Tsuji K, Yoshida N, Nakanishi H, Takemura K, Yamada S, Doyama H (2016) Recent traction methods for endoscopic submucosal dissection. World J Gastroenterol 22:5917-5926

4. Sakamoto N, Osada T, Shibuya T, Beppu K, Matsumoto K, Shimada Y, Konno A, Kurosawa A, Nagahara A, Ohkusa T, Ogihara $\mathrm{T}$, Watanabe $\mathrm{S}$ (2008) The facilitation of a new traction device (S-O clip) assisting endoscopic submucosal dissection for superficial colorectal neoplasms. Endoscopy 40(Suppl 2):E94-95

5. Sakamoto N, Osada T, Shibuya T, Beppu K, Matsumoto K, Mori H, Kawabe M, Nagahara A, Otaka M, Ogihara T, Watanabe S (2009) Endoscopic submucosal dissection of large colorectal tumors by using a novel spring-action S-O clip for traction (with video). Gastrointest Endosc 69:1370-1374
6. Ritsuno H, Sakamoto N, Osada T, Goto SP, Murakami T, Ueyama H, Mori H, Matsumoto K, Beppu K, Shibuya T, Nagahara A, Ogihara T, Watanabe S (2014) Prospective clinical trial of traction device-assisted endoscopic submucosal dissection of large superficial colorectal tumors using the S-O clip. Surg Endosc 28:3143-3149

7. Nagata M (2019) Modified attachment method using an S-O clip for gastric endoscopic submucosal dissection. VideoGIE 4:151-153

8. Nishide N, Ono H, Kakushima N, Takizawa K, Tanaka M, Matsubayashi H, Yamaguchi Y (2012) Clinical outcomes of endoscopic submucosal dissection for early gastric cancer in remnant stomach or gastric tube. Endoscopy 44:577-583

9. Ono H, Yao K, Fujishiro M, Oda I, Nimura S, Yahagi N, Iishi H, Oka M, Ajioka Y, Ichinose M, Matsui T (2016) Guidelines for endoscopic submucosal dissection and endoscopic mucosal resection for early gastric cancer. Dig Endosc 28:3-15

10. Imagawa A, Okada H, Kawahara Y, Takenaka R, Kato J, Kawamoto H, Fujiki S, Takata R, Yoshino T, Shiratori Y (2006) Endoscopic submucosal dissection for early gastric cancer: results and degrees of technical difficulty as well as success. Endoscopy 38:987-990

11. Ahn JY, Choi KD, Choi JY, Kim MY, Lee JH, Choi KS, Kim DH, Song HJ, Lee GH, Jung HY, Kim JH (2011) Procedure time of endoscopic submucosal dissection according to the size and location of early gastric cancers: analysis of 916 dissections performed by 4 experts. Gastrointest Endosc 73:911-916

12. Nagata S, Jin YF, Tomoeda M, Kitamura M, Yuki M, Yoshizawa H, Kubo C, Ito Y, Uedo N, Ishihara R, Iishi H, Tomita Y (2011) Influential factors in procedure time of endoscopic submucosal dissection for gastric cancer with fibrotic change. Dig Endosc 23:296-301

13. Ono S, Kato M, Nakagawa M, Imai A, Yamamoto K, Shimizu Y (2013) Outcomes and predictive factors of "not self-completion" in gastric endoscopic submucosal dissection for novice operators. Surg Endosc 27:3577-3583

14. Ono H, Kondo H, Gotoda T, Shirao K, Yamaguchi H, Saito D, Hosokawa K, Shimoda T, Yoshida S (2001) Endoscopic mucosal resection for treatment of early gastric cancer. Gut 48:225-229

15. Gotoda T (2005) A large endoscopic resection by endoscopic submucosal dissection procedure for early gastric cancer. Clin Gastroenterol Hepatol 3:S71-73

16. Sakamoto N, Osada T, Ritsuno H, Murakami T, Shibuya T, Tomiki Y, Watanabe S (2017) Endoscopic submucosal dissection of colorectal tumors using a traction device called the S-O clip [in Japanese]. Gastroenterol Endosc 59:1514-1523

17. Yamamoto K, Hayashi S, Nakabori T, Shibuya M, Ichiba M, Inada M (2012) Endoscopic submucosal dissection using endoclips to assist in mucosal flap formation (novel technique: "clip flap method"). Endoscopy 44(2):E334-335

18. Imaeda H, Hosoe N, Ida Y, Kashiwagi K, Morohoshi Y, Suganuma K, Nagakubo S, Komatsu K, Suzuki H, Saito Y, Aiura K, Ogata H, Iwao Y, Kumai K, Kitagawa Y, Hibi T (2009) Novel technique of endoscopic submucosal dissection using an external grasping forceps for superficial gastric neoplasia. Dig Endosc 21:122-127

19. Higuchi K, Tanabe S, Azuma M, Sasaki T, Katada C, Ishido K, Naruke A, Mikami T, Koizumi W (2013) Double-endoscope endoscopic submucosal dissection for the treatment of early gastric cancer accompanied by an ulcer scar (with video). Gastrointest Endosc 78:266-273

20. Yoshida N, Doyama H, Ota R, Takeda Y, Nakanishi H, Tominaga K, Tsuji S, Takemura K (2016) Effectiveness of clip-and-snare method using pre-looping technique for gastric endoscopic submucosal dissection. World J Gastrointest Endosc 8:451-457 
21. Chen PJ, Chu HC, Chang WK, Hsieh TY, Chao YC (2008) Endoscopic submucosal dissection with internal traction for early gastric cancer (with video). Gastrointest Endosc 67:128-132

22. Matsumoto K, Nagahara A, Sakamoto N, Suyama M, Konuma H, Morimoto T, Sagawa E, Ueyama H, Takahashi T, Beppu K, Shibuya T, Osada T, Yoshizawa T, Ogihara T, Watanabe S (2011) A new traction device for facilitating endoscopic submucosal dissection (ESD) for early gastric cancer: the "medical ring". Endoscopy 43(2):E67-68

23. Parra-Blanco A, Nicolas D, Arnau MR, Gimeno-Garcia AZ, Rodrigo L, Quintero E (2011) Gastric endoscopic submucosal dissection assisted by a new traction method: the clip-band technique. A feasibility study in a porcine model (with video). Gastrointest Endosc 74:1137-1141

24. Oyama T, Kikuchi Y, Shimaya S, Tomori T, Hotta K, Miyata Y, Yamada S (2002) Endoscopic mucosal resection using a hooking knife (hooking EMR) [in Japanese]. Stomach Intest 37:1151-1161

25. Suzuki S, Gotoda T, Kobayashi Y, Kono S, Iwatsuka K, YagiKuwata N, Kusano C, Fukuzawa M, Moriyasu F (2016) Usefulness of a traction method using dental floss and a hemoclip for gastric endoscopic submucosal dissection: a propensity score matching analysis (with videos). Gastrointest Endosc 83:337-346
26. Yoshida M, Takizawa K, Ono H, Igarashi K, Sugimoto S, Kawata N, Tanaka M, Kakushima N, Ito S, Imai K, Hotta K, Matsubayashi H (2016) Efficacy of endoscopic submucosal dissection with dental floss clip traction for gastric epithelial neoplasia: a pilot study (with video). Surg Endosc 30:3100-3106

27. Yoshida M, Takizawa K, Suzuki S, Koike Y, Nonaka S, Yamasaki Y, Minagawa T, Sato C, Takeuchi C, Watanabe K, Kanzaki H, Morimoto H, Yano T, Sudo K, Mori K, Gotoda T, Ono H (2018) Conventional versus traction-assisted endoscopic submucosal dissection for gastric neoplasms: a multicenter, randomized controlled trial (with video). Gastrointest Endosc 87:1231-1240

28. Hashimoto R, Hirasawa D, Iwaki T, Yamaoka H, Nihei K, Tanaka I, Chonan A, Takase K (2018) Usefulness of the S-O clip for gastric endoscopic submucosal dissection (with video). Surg Endosc 32:908-914

Publisher's Note Springer Nature remains neutral with regard to jurisdictional claims in published maps and institutional affiliations. 